\title{
Symptomatic Anterior Cervical Osteophyte Causing Dysphagia: Case Report, Imaging, and Review of the Literature
}

\author{
Yi-Ren Chen ${ }^{1}$, Kwang Sung ${ }^{2}$, Suzanne Tharin ${ }^{3}$ \\ 1. Department of Neurosurgery, Stanford University Medical Center 2. Department of Otolaryngology - \\ Head \& Neck Surgery, Stanford University School of Medicine 3. Department of Neurosurgery, Stanford \\ University School of Medicine
}

$\square$ Corresponding author: Yi-Ren Chen, yirenchen@stanford.edu

Disclosures can be found in Additional Information at the end of the article

\section{Abstract}

Anterior cervical osteophytes are found in 20-30\% of elderly patients. Rarely, severe osteophytes can cause dysphagia, dysphonia, and dyspnea. Here, we illustrate a case of severe dysphagia caused by a large post-traumatic osteophyte with oropharyngeal swallow study showing a significant mass effect on the pharynx and resolution following osteophytectomy. We also review the literature regarding the etiology, diagnosis, and treatment of symptomatic anterior cervical osteophytes.

Categories: Neurosurgery, Gastroenterology, Otolaryngology

Keywords: cervical osteophyte, osteophytectomy

\section{Introduction}

Greater than $75 \%$ of people aged 65 and older have varying degrees of cervical spine degenerative changes, including hypertrophic anterior cervical osteophytes [1-3]. Specifically, anterior cervical osteophytes have a prevalence of $20-30 \%$ in the elderly population [4]. Causes of cervical osteophytes include diffuse idiopathic skeletal hyperostosis, ankylosing spondylitis, degenerative changes, and prior trauma, including surgery [5]. Anterior cervical osteophytes are generally asymptomatic; however, in rare cases, they can lead to dysphagia, dysphonia, and dyspnea [6-7]. Such symptoms are generally correlated with the size of the hypertrophic spurs [8]. Here, we present a case of a 63-year-old man presenting with a large anterior osteophyte causing severe dysphagia, whose symptoms resolved following cervical osteophytectomy.

Received 01/19/2016 Review began 01/21/2016 Review ended 01/25/2016 Published 02/02/2016

C) Copyright 2016

Chen et al. This is an open access article distributed under the terms of the Creative Commons Attribution License CC-BY 3.0., which permits unrestricted use, distribution, and reproduction in any medium, provided the original author and source are credited.

\section{Case Presentation}

A 63-year-old man with a history of neck trauma resulting in vocal cord injury ten years prior presented with two years of progressive dysphagia. He was unable to swallow solid foods, and could tolerate only a puree and liquid diet. He had no dysphonia or dyspnea but did have some odynophagia on swallowing. He was otherwise healthy with no other medical history. Informed patient consent was obtained for treatment.

Computed tomography (CT) of the cervical spine showed a large anterior osteophyte spanning from C3 to C6 and measuring $19 \mathrm{~mm}$ at its greatest anteroposterior extent (Figure 1A, arrow). An oropharyngeal swallow study showed a significant mass effect on the pharynx and splitting of the contrast into two tracts (arrowheads) around the osteophyte (asterisk) during active swallow on the anteroposterior view (Figure $1 B$ ). In addition, cricopharyngeus $(\mathrm{CP})$ hypertrophy 


\section{Cureus}

with mild narrowing of the upper esophageal sphincter was observed (thin arrow). Aspiration of liquids and, to a lesser extent, pureed foods, was noted on swallow studies.

The patient underwent an anterior cervical osteophytectomy with concomitant CP myotomy. Bone wax was used intra-operatively to prevent bone regrowth [9]. A postoperative lateral plain film showed the removal of the anterior osteophyte (Figure 1C). The patient reported significant improvement of dysphagia immediately postoperatively and complete resolution of symptoms at his one-month follow-up. At his one-year follow-up, the patient continued to report resolution of his symptoms with normal swallow function. Of note, NSAIDs were administered postoperatively to prevent osteophyte regrowth [10].
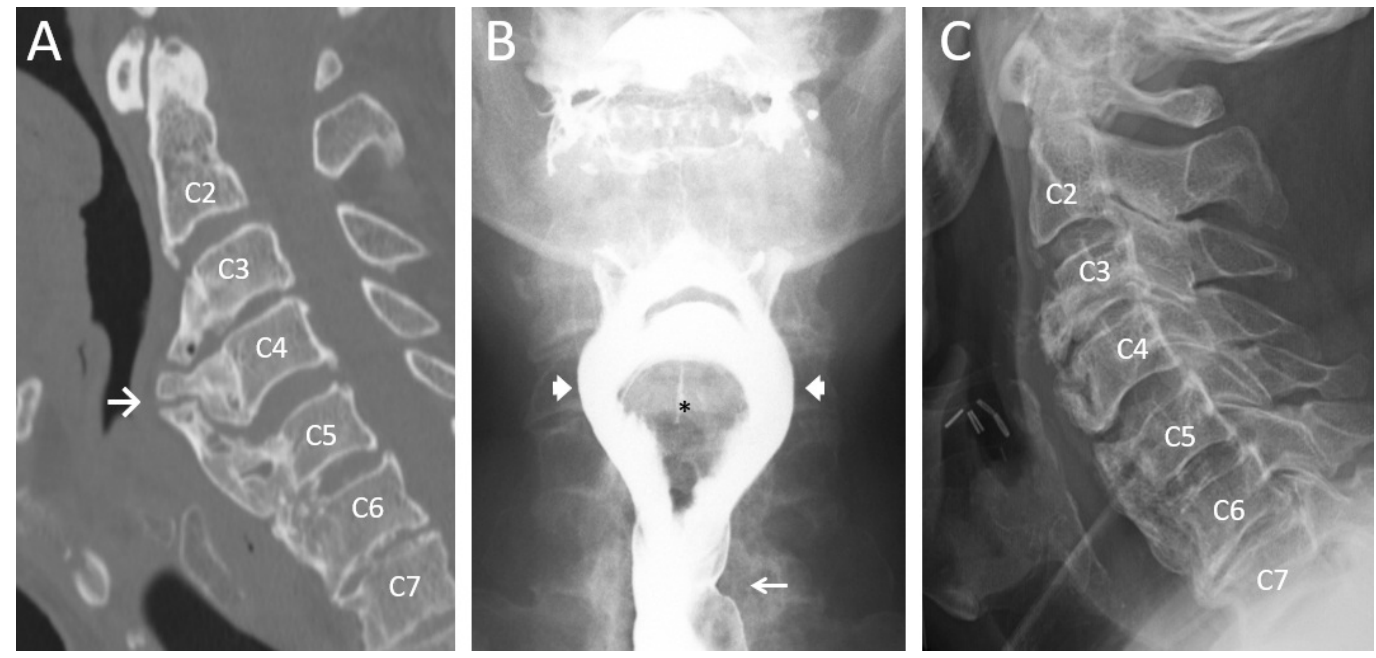

\section{FIGURE 1: Anterior cervical osteophyte before and after osteophytectomy}

\section{Discussion}

Osteophytes can form at any cervical level but are most common at C5-6 and C6-7, likely due to greater load-bearing and mobility [11]. Dysphagia in patients with anterior osteophytes may be explained by the fact that the esophagus rests on the anterior border of the cervical vertebrae from C4-7. Etiologies of dysphagia include a large osteophyte causing significant mechanical compression, a smaller osteophyte causing obstruction at the level of the cricoid cartilage, and inflammation secondary to local mass effect [12-15].

Most anterior cervical osteophytes are asymptomatic; however, they are not an uncommon cause of dysphagia. Interestingly, one study in the veteran population showed anterior cervical bony protrusion in $10.6 \%$ of patients over 60 years of age undergoing dysphagia evaluation, suggesting that the incidence of cervical osteophytes causing dysphagia is higher than recognized in the medical community, and underscoring their place in the differential diagnosis of dysphagia [16].

The diagnosis of cervical osteophytes may be accomplished with a CT scan, which can clearly define the bony anatomy. A barium swallow is essential to confirm the presence of esophageal compression by the cervical osteophyte. Magnetic resonance imaging (MRI) may also be considered in patients with additional symptoms, such as dyspnea and dysphonia, to identify any soft tissue damage, perforations, or superinfection. MRI is also useful to evaluate any concomitant central or foraminal cervical stenosis that the surgeon may wish to address at the 
time of osteophytectomy.

The mainstay of treatment for cervical osteophytes is conservative, including antiinflammatory medications and diet modification [17]. However, for patients in whom conservative management has failed, operative intervention may be considered. Some authors argue that cervical osteophytectomy should be considered in all patients with cervical osteophytes causing chronic dysphagia and dyspnea because of possible progression to acute respiratory distress. Maiuri, et al. reported a case of a patient with a two-year history of dysphagia who suffered sudden severe respiratory distress requiring emergency tracheotomy [18].

Surgery for cervical osteophytes has good long-term outcomes. Our patient continued to have symptomatic relief at his one-year follow-up. This is in keeping with a prior series published by Urrutia, et al. showing no recurrence of dysphagia and minimal radiographic regrowth at one to nine year (average 59.8 months) follow-up evaluations [19]. A second series published by Miyamoto, et al. reported immediate postoperative relief of dysphagia in all patients, but noted some radiographic recurrence at six- to 13-year follow-up evaluations (mean: nine years), with an average rate of regrowth of $1 \mathrm{~mm} /$ year [20]. Five out of seven of their patients remained asymptomatic, but two had moderate dysphagia 10 and 11 years after surgery, suggesting a low rate of late symptomatic recurrence [20].

\section{Conclusions}

Large anterior cervical osteophytes are a potential cause of dysphagia. The key imaging study is a barium swallow. Patients with significant symptoms who fail conservative management should be considered for osteophytectomy. Outcomes following osteophytectomy are very favorable.

\section{Additional Information}

\section{Disclosures}

Human subjects: Consent was obtained by all participants in this study. Conflicts of interest: In compliance with the ICMJE uniform disclosure form, all authors declare the following: Payment/services info: All authors have declared that no financial support was received from any organization for the submitted work. Financial relationships: All authors have declared that they have no financial relationships at present or within the previous three years with any organizations that might have an interest in the submitted work. Other relationships: All authors have declared that there are no other relationships or activities that could appear to have influenced the submitted work.

\section{References}

1. Kumaresan S, Yoganandan N, Pintar FA, Maiman DJ, Goel VK: Contribution of disc degeneration to osteophyte formation in the cervivcal spine: a biomechanical investigation. J Orthop Res. 2001, 19:977-84. 10.1016/S0736-0266(01)00010-9

2. Resnick D: Degenerative disease of the vertebral column . Radiology. 1985, 156:3-14. 10.1148/radiology.156.1.3923556

3. Seidler TO, Pèrez Alvarez JC, Wonneberger K, Hacki T: Dysphagia caused by ventral osteophytes of the cervical spine: clinical and radiographic findings. Eur Arch Otorhinolaryngol. 2009, 266:285-91. 10.1007/s00405-008-0735-4

4. Akbal A, Kurtaran A, Selcuk B, Gurcan A, Ersoz M, Akyuz M: The development of dysphagia and dysphonia due to anterior cervical osteophytes. Rheumatol Int. 2009, 29:331-34. 10.1007/s00296-008-0669-6

5. Resnick D, Shapiro RF, Wiesner KB, Niwayama G, Utsinger PD, Shaul SR: Diffuse idiopathic 
skeletal hyperostosis (DISH) [ankylosing hyperostosis of Forestier and Rotes-Querol]. Semin Arthritis Rheum. 1978, 7:153-87. 10.1016/0049-0172(78)90036-7

6. Brandenberg G, Leibrock LG: Dysphagia and dysphonia secondary to anterior cervical osteophytes. Neurosurgery. 1986, 18:90-93. 10.1227/00006123-198601000-00016

7. Fuerderer S, Eysel-Gosepath K, Schröder U, Delank KS, Eysel P: Retro-pharyngeal obstruction in association with osteophytes of the cervical spine. J Bone Joint Surg Br. 2004, 86:837-40.

10.1007/s12070-011-0334-3

8. Bruno E, Alessandrini M, De Angelis E: Giant cervical hyperostosis of the prevertebral space: presentation of two cases and review of the literature (Article in Italian). Acta Otorhinolaryngol Ital. 1996, 16:532-36. 10.1016/j.anorl.2010.05.002

9. Vestergaard RF, Jensen H, Vind-Kezunovic S, Jakobsen T, Søballe K, Hasenkam JM: Bone healing after median sternotomy: a comparison of two hemostatic devices. J Cardiothorac Surg. 2010, 5:117. 10.1186/1749-8090-5-117

10. Pountos I, Georgouli T, Calori GM, Giannoudis PV: Do nonsteroidal anti-inflammatory drugs affect bone healing? A critical analysis. ScientificWorldJournal. 2012, 2012:606404. 10.1100/2012/606404

11. Schmidek HH: Cervical spondylosis. Am Fam Physician. 1986, 33:89-99.

12. Klaassen Z, Tubbs RS, Apaydin N, Hage R, Jordan R, Loukas M: Vertebral spinal osteophytes. Anat Sci Int. 2011, 86:1-9. 10.1007/s12565-010-0080-8

13. Lambert JR, Tepperman PS, Jimenez J, Newman A: Cervical spine disease and dysphagia. Four new cases and a review of the literature. Am J Gastroenterol. 1981, 76:35-40.

14. Crowther A, Ardran GM: Dysphagia due to cervical spondylosis. J Laryngol Otol. 1985, 99:1167-69. 10.1017/S0022215100098352

15. Di Vito J: Cervical osteophytic dysphagia: single and combined mechanisms . Dysphagia. 1998, 13:58-61. 10.1007/PL00009550

16. Granville LJ, Musson N, Altman R, Silverman M: Anterior cervical osteophytes as a cause of pharyngeal stage dysphagia. J Am Geriatr Soc. 1998, 46:1003-7. 10.1111/j.15325415.1998.tb02757.x

17. Laus M, Malaguti MC, Alfonso C, Ferrari D, Zappoli FA, Giunti A: Dysphagia due to cervical osteophytosis. Chir Organi Mov. 1995, 80:263-71.

18. Maiuri F, Stella L, Sardo L, Buonamassa S: Dysphagia and dyspnea due to an anterior cervical osteophyte. Arch Orthop Trauma Surg. 2002, 122:245-47. 10.1007/s00402-001-0369-0

19. Urrutia J, Bono CM: Long-term results of surgical treatment of dysphagia secondary to cervical diffuse idiopathic skeletal hyperostosis. Spine J. 2009, 9:e13-7.

10.1016/j.spinee.2009.04.006

20. Miyamoto K, Sugiyama S, Hosoe H, Iinuma N, Suzuki Y, Shimizu K: Postsurgical recurrence of osteophytes causing dysphagia in patients with diffuse idiopathic skeletal hyperostosis. Eur Spine J. 2009, 18:1652-58. 10.1007/s00586-009-1133-3 